\title{
Endoscopic ultrasound-guided gastrojejunostomy: a novel technique
}

Endoscopic ultrasound (EUS)-guided gastroenterostomy with placement of a lumen-apposing metal stent has emerged as a novel, minimally invasive therapeutic option for patients with gastric outlet obstruction (GOO) [1 - 3]. The most challenging aspect of the procedure is immobilizing the jejunal loop in order to create the fistulous tract and deploy the stent. Several different techniques have been described [1-3]. We present a novel approach involving the use of a second endoscope that is advanced through a previously placed percutaneous gastrostomy (PEG) site to within the target jejunal lumen in order to provide traction on the wire, and to facilitate fistula creation and stent placement.

A 68-year-old man presented with GOO following surgical resection for pancreatic cancer. Enteral stenting and PEG-jejununostomy tube placement were unsuccessful for palliation. Therefore, EUSguided gastroenterostomy was performed using a novel rendezvous technique ( $\triangleright$ Video 1$)$.

The echoendoscope was used to identify and access the jejunum from within the gastric lumen, and a wire was advanced into the targeted jejunal loop. A concur-

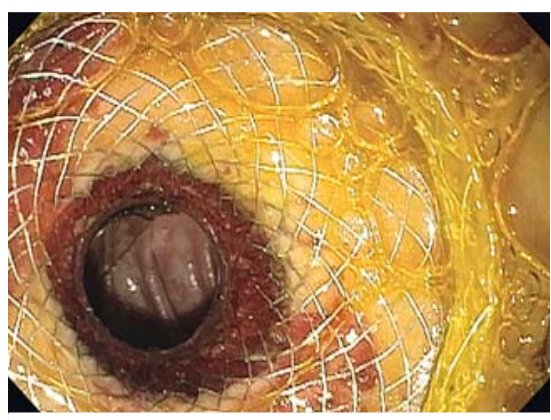

- Fig. 1 Endoscopic image of a gastrojejunal lumen-apposing metal stent. rent small-diameter endoscope was advanced percutaneously through the PEG site and across the malignant obstruction into the jejunum, where the coiled guidewire was visualized and grasped by a pediatric biopsy forceps. This provided traction on the wire, which facilitated transgastric cautery-assisted fistula creation and stent placement with a lumen-apposing metal stent ( Fig.1). After stent placement, both endoscopes were removed and the PEG site was closed intragastrically with an over-the-scope clip. At 3-month followup, the patient was still able to tolerate a soft diet.

In conclusion, EUS-guided gastroenterostomy using this rendezvous technique was safe and efficacious, and should be considered in patients with GOO who have a previously placed PEG tube.

Endoscopy_UCTN_Code_TTT_1AS_2AB

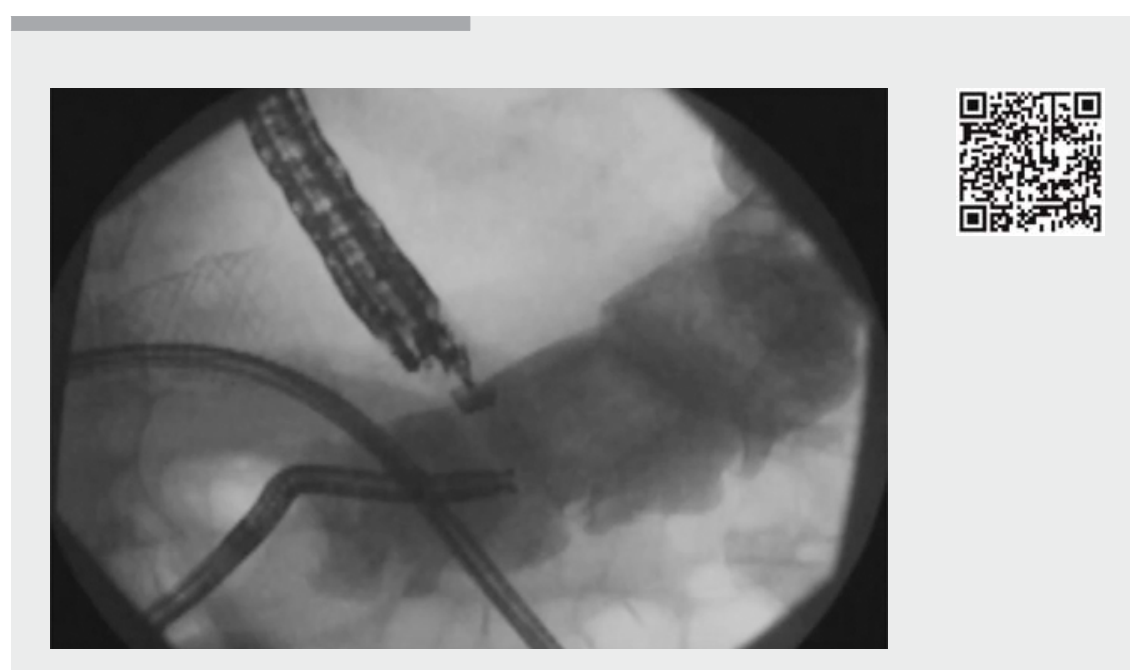

$\checkmark$ Video 1 Endoscopic ultrasound-guided gastroenterostomy using a novel rendezvous technique.

\section{Competing interests}

Michel Kahaleh MD: has received grant support from Boston Scientific, Fujinon, EMcison, Xlumena Inc., W.L. Gore, MaunaKea, Apollo Endosurgery, Cook Endoscopy, ASPIRE Bariatrics, GI Dynamics, NinePoint Medical, Merit Medical, Olympus and MI Tech. He is a consultant for Boston Scientific, Xlumena Inc., Concordia Laboratories Inc, ABBvie, and MaunaKea Tech.

All other authors have no conflicts of interest to report.

\section{The Authors}

Amy Tyberg, Manuel Perez-Miranda, Steven Zerbo, Todd H. Baron, Michel Kahaleh

Division of Gastroenterology and Hepatology, Weil Cornell Medical, New York, United States 


\section{Michel Kahaleh, MD}

Division of Gastroenterology and

Hepatology, Weill Cornell Medical College,

New York, NY 10021, United States

Fax: +1-646-962-0110

mkahaleh@gmail.com

\section{References}

[1] Tyberg A, Perez-Miranda M, Sanchez-Ocana $R$ et al. Endoscopic ultrasound-guided gastrojejunostomy with a lumen-apposing metal stent: a multicenter, international experience. Endosc Int Open 2016; 4:

E276-E281
[2] Itoi T, Ishii K, Ikeuchi $\mathrm{N}$ et al. Prospective evaluation of endoscopic ultrasonographyguided double-balloon-occluded gastrojejunostomy bypass (EPASS) for malignant gastric outlet obstruction. Gut 2016; 65: 193 195

[3] Khashab MA, Kumbhari V, Grimm IS et al. EUS-guided gastroenterostomy: the first $U$. S. clinical experience (with video). Gastrointest Endosc 2015; 82: 932 - 938

\section{Bibliography}

DOI https://doi.org/10.1055/s-0043-115886

Published online: 31.7.2017

Endoscopy 2017; 49: E252-E253

(c) Georg Thieme Verlag KG

Stuttgart · New York

ISSN 0013-726X
ENDOSCOPY E-VIDEOS

https://eref.thieme.de/e-videos

口回 Endoscopy E-Videos is a free Fection, reporting 然: on interesting cases and new techniques in gastroenterological endoscopy. All papers include a high quality video and all contributions are freely accessible online.

This section has its own submission website at https://mc.manuscriptcentral.com/e-videos 